\title{
Устойчивое развитие Арктики. Сложные проблемы энергетической и экологической безопасности
}

\author{
Эрика М. Дингман *
}

Овладевание залежами углеводородов в Арктике является стратегическим приоритетом как арктических государств, так и ряда государств неарктических. Геологическая служба США считает, что территория севернее арктического полярного круга содержит 13 процентов неразведанных мировых запасов нефти и 30 процентов неразведанных запасов природного газа. Предполагается, что 84 процента этих запасов находятся в море. Увеличение глобального спроса на энергию, связанное в основном с ростом населения и доходов, вместе с техническим прогрессом и финансовыми льготами, по-видимому, ускорят темпы, с которыми заинтересованные стороны проводят разведку предполагаемых арктических запасов углеводородов. ${ }^{1}$

Несколько негосударственных и государственных организаций одновременно применяют разные меры для ограничения эмиссий парниковых газов (ПГ) - от финансовых льгот и регуляторных схем, направленных на ускорение развития и внедрение возобновляемых источников энергии до убедительных заявлений, касающихся неблагоприятных эффектов климатических изменений. Эти участники признают, что вечный голод на невозобновляемые ресурсы не является разумной альтернативой в долгосрочном плане. В то время как оказалось, что исключительно трудно задействовать многосторонние соглашения по климатическим изменениям, такие как протокол Киото, региональные сети сторон-единомышленников достигли существенного успеха. Примерами таких сетей являются Приполярный совет инуитов и Европейский союз. Обе организации внесли существенный вклад в разработку вопросов, связанных с последствиями зависимости от углеводородов, хотя и с весьма различных точек зрения.

\footnotetext{
Эрика Дингман является ассоциированным научным сотрудником Института мировой политики, что находится в Нью-Йорк сити. Ее исследование сфокусировано на широком спектре вопросов, относящихся к изменению климата в Арктике. Арктика все больше становится фокусом государственной политики и международных отношений заинтересованных кругов как геополитического театра Арктики, так и неарктических сторон. В этом контексте предметом исследования Эрики Дингман является взаимосвязь между изменениями климата, разведки углеводородов и минералов и политического участия инуитов, одной из коренных арктических групп. Ранее она была ассоциированным исследователем в Lower Manhattan Project, субсидированном Департаментом энергетики США. Имеет степень магистра в области международных отношений, полученную в Нью-йоркском университете The New School.

1 Согласно Энергетическому обзору 2030 компании Бритиш Петролеум, спрос на нефть будет уменьшаться, в то время как спрос на конвенциональный и неконвенциональный газ будет расти. Однако, неископаемые виды горючего и на первом месте возобновляемые источники энергии обеспечивают половину роста спроса на энергию. BP Energy Outlook 2030 (London: British Petroleum, January 2011).
} 
Приполярный совет инуитов (ПСИ) — группа, представляющая интересы инуитов Канады, Дании, России и Соединенных Штатов-основательно занялся равновесием между сохранением их родных земель и потенциальными социально-экономическими выгодами добычи углеводородов. Вместо того, чтобы сосредотачиваться исключительно на добычу энергетических ресурсов, Европейский Союз (ЕС) ищет путей уменьшения эмиссий ПГ в регионе и рассматривает возобновляемые источники энергии как средство расширения энергийной независимости и увеличения экономического роста. ${ }^{2}$ И ПСИ и ЕС ищут решения трудных проблем, ставят ребром вопросы, которые противоречат нынешнему статус-кво. И ПСИ и ЕС борются за большее влияние в определении Арктической стратегии. ПСИ является постоянным членом Арктического совета (АC), но в отличие от индивидуальных стран Арктики не имеет права голоса. ЕС пока не является членом Арктического совета и стремится к статусу постоянного наблюдателя. И ПСИ и ЕС имеют стратегический интерес к доступу к арктическим ресурсам.

При рассмотрении потенциала арктических углеводородов нужно также иметь в виду последствия расширения их добычи. Могут ли ПСИ и ЕС действовать в роли противовеса арктических государств, весьма сильно заинтересованных в добыче углеводородов?

Как писал Саймон Далби: «Предположение, что окружающая среда является чем-то отдельным, как от человечества, так и от экономических систем, лежит в основе затруднений при проведении политики устойчивого развития и обеспечения безопасности». ${ }^{3}$

\section{Экологические вызовы}

Изменение климата является самой значимой глобальной переменной двадцать первого века. Согласно Шийле Уат-Клотье, бывшему председателю ПСИ, «Арктика как канарейка в угольной шахте для глобальной окружающей среды». ${ }^{4}$ Джой Комизо, старший научный сотрудник Центра космических полетов им. Годдарда (NASA), заявляет: «Количество морского льда не только уменьшается, темп его сокращения драстически увеличивается». Это является признаком тенденции к потеплению, которая будет иметь экологические, социально-экономические и связанные с безопасностью последствия. ${ }^{5}$

2 European Commission, Climate Action: The EU Climate and Energy Package (последнее обновление 18 октября 2010); доступно на http://ec.europa.eu/clima/policies/package/index_ en.htm.

3 Simon Dalby, "Security and Ecology in the Age of Globalization," Environmental Change and Security Project Report 8 (Summer 2002): 101.

4 Inuit Circumpolar Council Press Release, "Inuit of Canada Amongst the Hardest Hit by Climate Change," (30 August 2000); доступно на http://inuitcircumpolar.com/index.php?ID=137\& Lang=En.

5 Patrick Lynch, “Arctic Sea Ice Continues Decline, Hits 2nd-Lowest Level," NASA News Feature (4 October 2011); доступно на http://www.nasa.gov/topics/earth/features/2011-icemin.html. 
Таяние вечной мерзлоты наносит вред существующей инфраструктуре. Производственные и жилищные строения получают серьезные повреждения или разрушаются. Ледовые дороги становятся неиспользуемыми и железнодорожные рельсы искривляются. По мере уменьшения устойчивости вечной мерзлоты, трубы нефтепроводов сдвигаются, увеличивая риск нефтяных разливов. Коммерческий интерес рассчитывает на надежность вечной мерзлоты для транспортировки товаров к шахтам и буровым установкам. Согласно исследованию эффектов потепления в Арктике, проведенных Калифорнийским университетом в Лос-Анжелесе, ожидается, что известная Северо-Канадская «бриллиантовая дорога», Тибит-Коктвойто, предположительно самая прибыльная ледовая дорога, пострадает от таяния вечной мерзлоты. ${ }^{6}$ Для отдаленных общин коренных жителей неиспользуемые зимние дороги заставят их «перейти на воздушные перевозки, что драматически увеличит цену поставок», отмечает Скотт Стивенсон, ведущий автор этого исследования.

В исследовании, однако, также отмечается, что прибрежные поселения, вероятно, выиграют от увеличения межконтинентальных морских перевозок и морские государства Арктики, соответственно, будут иметь лучший доступ к своим исключительным экономическим зонам, включая рыболов и добычу углеводородов. Хотя государства и корпорации без сомнения получат выгоду от оживления деловой активности, в какой степени общности коренного населения тоже будут иметь свою долю социально-экономических выгод, остается под вопросом.

Ускоренная эрозия береговой линии Арктики также является угрозой для уязвимых общин. Вынужденное перемещение деревень инуитов Аляски уже реальность, которая определяет то, что можно назвать первыми климатическими беженцами США. Согласно докладу Счетной палаты США за 2004 год, четыре деревни оказались в непосредственной опасности в результате затоплений и эрозии почвы. К 2009 году их число увеличилось до тридцати одной, двенадцать из которых решили переехать. Однако, многочисленные осложнения замедляли процесс, в том числе цена переезда в размере 95-200 миллионов долларов США на деревню, трудности в выборе культурно-приемлемого местоположения и психологическая травма при отделении семей от традиций многих поколений. ${ }^{7}$

С экономической точки зрения, тенденция потепления в Арктике имеет потенциальные последствия, идущие значительно дальше тех, которые наблюдались до сих пор. Николас Стерн из Лондонской школы экономики отмечает, что большая часть научных анализов консервативны в отношении долгосрочных прогнозов климатических изменений. ${ }^{8}$ До последнего времени большая часть моделей Межправи-

6 Scott R. Stephenson, Laurence C. Smith, and John A. Agnew, "Divergent Long-term Trajectories of Human Access to the Arctic," Nature Climate Change (29 May 2011): 156-60; доступно на www.nature.com/nclimate/journal/v1/n3/full/nclimate1120.html.

7 Tribes \& Climate Change, "Climate Change: Realities of Relocation for Alaska Native Villages"; доступно на www4.nau.edu/tribalclimatechange/tribes/ak_inupiaq_AkRelocation.asp.

8 Nicholas Stern, "Climate Change: The Economics of and Prospects for a Global Deal," video produced by the MIT Energy Initiative (19 November 2007); доступно на http://mitworld.mit.edu/video/536. 
тельственной группы экспертов по климатическим изменениям (МГЭКИ) не учитывали опасность, проистекающую от таяния вечной мерзлоты. В результате далеко идущие последствия этого аспекта глобального потепления не учитывались.

Причины для тревоги также создают новопоявляющиеся источники загрязнения окружающей среды. Исследование МПКИ полагает, что таяние вечной мерзлоты в результате высвободит к концу века мегатонны углерода. ${ }^{9}$ Дополнительно к этому, отступающий морской лед приведет к повторному появлению устойчивых органических загрязнителей (УОЗ), уровень которых сейчас понизился. ${ }^{10}$ УОЗ являются результатом промышленных загрязнителей, произведенных где-то в другом месте, большая часть из которых оседает в районе Арктики.

\section{Нефтяные разливы и ответная реакция}

Тенденция потепления в Арктике также увеличивает возможность доступа к потенциальным месторождениям углеводородов, в том числе доступа к бурению глубоководных нефтяных полей, находящихся на большом расстоянии от берега. Однако, в случае утечки углеводородов, это расстояние создает существенно более опасные условия для операций по поиску и спасению (ПИС) также и для тех, кто будет заниматься очисткой. Вероятный рост морских перевозок и добычи углеводородов увеличивает присущий риск утечек нефти и последствий для окружающей среды, а для прибрежных общин проистекающие потери скорее всего будут долгосрочными. Доклад Национальной океанической и атмосферной администрации США (НОАА) указывает, что в 1989 году при нефтяном разливе Ексон Валдез 11 миллионов галлонов нефти вылилось в Пролив Принца Уильяма на побережье Аляски. В то время как компания Ексон объявила, что основная часть работ по очистке была закончена в течении трех лет, доклад отмечает, что десятки лет после этого свидетельства разлива все еще присутствуют на берегах Аляски, проявляясь, например, в уменьшении рыбных запасов и в заражении раковин и мидий. Нефтяной разлив Ексон Валдез произошел в условиях относительно спокойного моря, что не является характерным для вод Арктики. ${ }^{11}$

В 2009 году в Исследовательском центре береговой реакции при университете Нью-Хемпшира собрались эксперты из правительства, НПО и коренных арктических групп, чтобы рассмотреть риски увеличенной активности, связанной с разведкой и добычей углеводородов в Арктике. Сценарии, которые сочли вероятными, были рассмотрены с целью оценить нехватку потенциалов для проведению опера-

9 Emily Chung, "Arctic Permafrost Thaw Will Boost Carbon Emissions," CBC News: Technology and Science (15 August 2011); доступно на www.cbc.ca/news/technology/story/2011/08/15/ science-carbon-sink-source-arctic.html.

10 Jianmin Ma, Hayley Hung, Chongguo Tian, and Roland Kallenborn, "Revolatilization of Persistent Organic Pollutants in the Arctic Induced by Climate Change," Nature Climate Change 1:5 (24 July 2011) 255-60; доступно на http://www.nature.com/nclimate/journal/v1/n5/full/ nclimate1 167.html?WT.ec_id=NCLIMATE-201108\#auth-4.

11 United States Department of Commerce, National Oceanic and Atmospheric Administration, "NOAA's Office of Response and Restoration: Arctic Activities" (March 2009). 
ций по поиску и спасению и по восстановлению окружающей среды. Было обнаружено множество недостатков, включая несоответствующий флот спасательных морских судов; отличающиеся друг от друга и несовместимые национальные политики, плохая коммуникационная инфраструктура; устаревшие или неполные данные об окружающей среде; тяжелые социально-экономические последствия для коренных народов; экологическая деградация. Менее очевидные слабости включали языковой барьер; несоответствующие береговые ресурсы для обеспечения крова и заботы для больших групп пострадавших и команд спасателей; нерешительность правительства при предоставлении портов спасения для поврежденных морских судов; связанные со всем этим расходы правительства/правительств, ответственных за операции по поиску, спасению и очистке. ${ }^{12}$

Др. Абдел Хонейм, главный ведущий инженер в Det Norske Veritas, фонда, занимающегося менеджментом риска с фокусом на морскую нефть, газ и энергетику, отмечает: «Мы на самом деле не подготовлены к катастрофе [в Арктике]». Хотя Хонейм утверждает, что промышленность располагает соответствующими технологиями развивать глубоководные буровые установки, он также считает, что в большей степени должны быть подключены регулирующие органы. Анализ риска и готовность к чрезвычайным ситуациям остаются первостепенными вызовами для углеводородных компаний, оперирующих в Арктике. ${ }^{13}$ Адмирал Роберт Папп из Береговой охраны США также выразил озабоченность экологическими последствиями разлива нефти в Арктике. Ведомство «нуждается в соответствующем уровне потенциала реагирования на загрязнение в Арктике. К настоящему моменту мы не имеем такового». ${ }^{14}$

12 Coastal Response Research Center at the University of New Hampshire, Opening the Arctic Seas: Envisioning Disasters and Framing Solutions (Durham, NH: conference report issued January 2009; conference held 18-20 March 2008). Ожидается что ответственные стороны принимают на себя расходы по очистке нефтяных разливов. Однако, как в 2010 году показала утечка с платформы Deepwater Horizon в Мексиканском заливе, федеральная, штатская и местная администрации несут существенную часть расходов. Многочисленные факторы имеют значение при определении, какая сторона должна нести расходы на операции по поиску и спасению и по восстоновлению экологии. К примеру, в США был учрежден Трастовой Фонд Ответственности за Разливы Нефти с целью оплачивать определенные расходы при нефтяных разливах. Однако, фонд ограничен одним миллиардом долларов США на инцидент и существовал риск, что в 2010 году этот потолок будет достигнут. Для дополнительной информации смотри GAO-11-90R Deepwater Horizon Oil Spill: Preliminary Assessment of Federal Financial Risks and Cost Reimbursement and Notification Policies and Procedures (Washingotn, D.C.: GAO, 12 November 2010).

13 Abdel Ghoneim, "Meeting the Challenges of Arctic Development," Offshore Magazine webcast (24 February 2011); доступно на www.offshore-mag.com/index/webcasts/webcast-display/ 1403483920/webcasts/webcasts-offshore/live-events/os-arctic.html.

14 Stephen Lacey, “After North Sea Oil Spill, Shell Plans to Continue Arctic Drilling," Grist (16 August 2011); доступно на http://grist.org/fossil-fuels/2011-08-16-after-north-sea-oil-spillshell-plans-continue-arctic-drilling. 


\section{Приполярный совет инуитов и Европейский союз: необычные союзники}

Есть ли у союза ПСИ-ЕС потенциал быть противовесом коммерческому импульсу развития Арктики? Как указывалось выше, обе организации ищут решение сложных проблем, обе не боятся ставить трудные вопросы, являющиеся вызовом ранее приобретенной мудрости. Но потенциал союзничества не без своих усложнений. Асимметричная история обеих организаций может свести на нет любую идею о союзе, основанном на общей воле бороться с климатическими изменениями. И всетаки есть основания рассматривать возможность сотрудничества между ПСИ и ЕС.

\section{Приполярный совет инуитов и развитие Арктики}

Основанная в 1977 году, Приполярная конференция инуитов (ныне - Совет) является трансграничной организацией, представляющей интересы инуитов Канады, Аляски, Гренландии и России. Со дня основания его основной целью было «сохранение окружающей среды в Арктике и выработка комплексной Арктической политики». ${ }^{15}$ Арктический ученый Джессика Шедиан положительно оценивает политическое упорство ПСИ и рациональные кампании в средствах массовой информации, которыми Совет завоевал себе репутацию «влиятельного политического действующего лица». ${ }^{16}$

Когда ПСИ только еще зарождался, его основатель Эбен Хопсон написал письмо президенту США Джимми Картеру, в котором заявлял: «Мы надеемся, что наша Приполярная конференция инуитов инициирует диалог между пятью прибрежными арктическими нациями, который должен предшествовать формальным соглашениям по безопасному и ответственному развитию добычи нефти и газа». ${ }^{17}$ Хотя и развитие добычи углеводородов считалось проблематичным, но оно принесло бы тепло в дома инуитов, что было существенным аргументом в его пользу. В 1981 в статье в Foreign Affairs отмечалось, что «пионерами трансарктической дипломатии были не правительства шести прилегающих стран», а инициативы ПСИ. ${ }^{18}$ Формализация трансарктической дипломатии произошла с учреждением Арктического совета в 1996.

В 2000 году ПСИ имел достаточный авторитет, чтобы оказать влияние на создаваемый Арктическим советом Рамочный документ по устойчивому развитию. Руководящие принципы Рамочного документа предполагали, что устойчивое развитие

15 Jessica Shadian, "Remaking Arctic Governance: The Construction of an Arctic Inuit Polity," Polar Record 42 (2006): 249-59.

16 Jessica Shadian, "From States to Polities: Reconceptualizing Sovereignty through Inuit Governance," European Journal of International Relations 16:3 (2010): 485-510.

17 Цитировано из Shadian, "Remaking Arctic Governance."

18 Lincoln P. Bloomfield, "The Arctic: Last Unmanaged Frontier," Foreign Affairs 60:1 (1981): 90 . 
должно включать «возможность защищать и улучшать экологию, экономику, культуру и здоровье общин коренных народов и других обитателей Арктики». ${ }^{19}$

Когда Программа оценки влияния изменения арктического климата (ОВИАК), принятая Арктическим советом, была готова к выпуску в свет, Соединенные Штаты попытались отложить ее опубликование на неопределенное время. Шийла УаттКлотье задействовала свои связи в Вашингтоне, чтобы продвинуть публикацию доклада. По ее требованию сенаторы Мак-Кейн, Лаунтенберг и Сноуи вмешались, и ОВИАК вышла в свет в ноябре 2004, как и планировалось. Для ПСИ программа ОВИАК была средством «заполнить пропасть между реакцией Европы и Америки на изменение глобального климата». ПСИ приветствовал привлечение других неарктических государств, включая Европейский союз, дополняя, что Объединенное королевство особенно активно участвовало в работе Арктического совета. ${ }^{20}$

Многие в общности инуитов связывают это устойчивое развитие с культурными и экономическими последствиями доминирования Запада. Тогда как исторические процессы колонизации создавали искусственные границы и пытались уничтожить традиции и культуру инуитов, Аккалук Линге, нынешний председатель ПСИ, связывает изменение климата с историческим «изменяющим культуру» влиянием миссионеров и колонизаторов. ${ }^{21}$

Непринятие традиционного колониализма также видно в принятой ПСИ Декларации о суверенитете приполярных инуитов в Арктике. Декларация подчеркивает значение сотрудничества между арктическими странами и коренными народами. Это было особенно важно в свете встречи в 2008 году прибрежных государств: Канады, Дании, Норвегии, России и Соединенных Штатов.

Неофициально известные как Арктика 5, эти государства вместе написали в 2008 году Илулисатскую декларацию, которая, похоже, саботирует дух сотрудничества в Арктическом совете. Брукс Ийгр, бывший Помощник государственного секретаря по окружающей среде и развитию, заметил, что эта встреча могла обозначать попытку Арктики 5 играть «доминирующую роль» в принятии решений относительно Арктики. Ийгр отмечает, что «такая точка зрения, очевидно, является вызовом для потенциала неприбережных арктических наций и неарктических госу-

19 Arctic Council, Framework Document (Chapeau) for the Sustainable Development Programme (13 October 2000); доступно на http://arctic-council.org/section/documentation.

20 Sheila Watt-Cloutier, Climate Change and the Arctic: Bringing Inuit Perspectives to Global Attention, Inuit Circumpolar Council, Address to the Norwegian Research and Technology Forum in cooperation with the Carnegie Institution second Trans-Atlantic Cooperative Research Conference, "Meeting the Climate-Energy Challenge" (Washington, D.C., 5 October 2004); доступно на www.inuitcircumpolar.com/index.php?ID=271\&Lang=En.

21 Aqqaluk Lynge, "Strengthening Culture through Change: Will Climate Change Strengthen or Destroy Us?," Luncheon Address at the University of Edinburgh, Scotland (2009); доступно на www.inuit.org/index.php?id=280\&L=1. 
дарств предъявлять права и защищать интересы к ресурсам или упражнять влияние на распоряжение ими». 22

Инуиты, однако, вознамериваются упражнять свои права на все арктические ресурсы, некоторые из которых защищены разными международными и местными законами. Тогда как Декларация о суверенитете касается природных ресурсов, Нунавутская Декларация приполярных инуитов о принципах развития ресурсов от 2011 года предполагает, что ПСИ ориентируется на условно-агрессивный подход к развитию природных ресурсов, связанный с управлением инуитов и теми социально-экономическими выгодами, что будут аккумулироваться для инуитских народов. В Декларации 2011 года отмечается, что развитие невозобновляемых энергетических ресурсов может внести свой вклад в «экономическое и социальное развитие инуитов как через каналы частного сектора (занятость, доходы, деловая активность), так и по каналам публичного сектора (доходы от земель публичной собственности, средства от налогов, инфраструктура)».

Все-таки разные степени национальной автономии вместе с варьирующим доступом в обозримом будущем к природным ресурсам ослабили окончательный итог декларации о ресурсах. Тогда как лидеры хотели навязать более сильные ограничения на развитие ресурсов, разногласия насчет степени развития привели к более гибкому набору руководящих принципов. Под преобладающим влиянием предстоящего доступа Гренландии к производству углеводородов, лидеры Гренландии рассматривали развитие как возможность добиться экономической независимости от Дании. Премьер Куупик Клейст заявил: «Компании извне веками эксплуатировали природные ресурсы арктических регионов. В отличие от инуитов. Теперь наша очередь». ${ }^{23}$ В самом деле, большой парадокс принятия решений инуитами кроется в связи экологической безопасности и социально-экономического развития.

\section{Европейский союз и развитие Арктики}

Когда арктическая политика Европейского союза полностью определится, многие предположат, что она сфокусируется скорее на изменении климата и вопросах экологии, чем на проблемах энергетической безопасности, что в некоторой степени соответствует политике ПСИ. ${ }^{24}$ В то же время, ЕС стратегически заинтересован в использовании арктических ресурсов. Однако, в лучшем случае, ЕС мог бы расширить свою политику по климатическим изменениям в Арктике, связывая уменьшение эмиссий с энергетической безопасностью и экономическим ростом.

22 Brooks B. Yeager, "The Ilulissat Declaration: Background and Implications for Arctic Governance," paper prepared for the Aspen Dialogue and Commission on Arctic Climate Change (5 November 2008).

23 Sarah Rogers, "Arctic Resource Development Inevitable and Safe: Greenland," Nunatsiakonline.ca (24 February 2011); доступно на http://www.nunatsiaqonline.ca/stories/article/ 240124_arctic_resource_development_inevitable_safe_greenland.

24 Kristine Offerdal, "Arctic Energy and EU Policy: Arbitrary Interest in the Norwegian High North," Arctic 63:1 (2010): 30-42. 
В 2009 ЕС принял юридически обязывающее документы, известные как Цели «20-20-20». К 2009 эмиссии ПГ для всего ЕС-27 уменьшились на 17.4 процентов по сравнению с уровнем 1990 года, что частично было достигнуто за счет развития возобновляемых источников энергии. Однако, в отличии от Канады, ЕС в целом является импортером энергии, что делает развитие возобновляемых источников энергии относительно непротиворечивым. «Климатическая политика ЕС», отмечает Миранда Шреурс, «рассматривается как способ сдвига экономик стран-членов к большей энергетической автономии, к эффективному использованию ресурсов и к технологическому прогрессу». ${ }^{25}$

Хотя поддержка схемы уменьшения эмиссий и не одобряется единогласно, некоторые страны, такие как Объединенное королевство, были особенно агрессивными в осуществлении редукции углеродных эмиссий. В 2008 году Акт об изменении климата стал первым юридически обязывающим документом по климатическим изменениям; была поставлена цель к 2050 году добиться уменьшения эмиссий на 80 процентов. Эта политика получила сильную политическую и общественную поддержку. Являясь когда-то поставщиком нефти и газа, Объединенное королевство теперь должно ориентироваться на другие опоры энергетической безопасности, в том числе и на возобновляемые источники. ${ }^{26} \mathrm{~K}$ тому же исследования показали, что повышающийся уровень моря будет оказывать влияние на экологическую и экономическую безопасность Великобритании. Исследование от 2010 года, проведенное Парламентской комиссией по науке и технологиям показывает, что в Объединенном королевстве инфраструктура и ресурсы стоимостью в 120 миллиардов паундов подвергаются риску от прибрежных затоплений и еще на 10 миллиардов паундов - от береговой эрозии. ${ }^{27}$ Кроме как в местной и региональной политике по климату, Европейский союз заинтересован в формировании стратегии и политики относительно Крайнего Севера. Арно Бехренс, эксперт по зависимости энергетики и климатических изменений, отмечает: «Переход Европы на низкоуглеродную энергетическую систему имеет смысл только в контексте глобального уменьшения углеродных эмиссий». ${ }^{28}$

После аварии на платформе Deepwater Horizon компании Бритиш Петролеум в 2010 году, Парламентский комитет по промышленности, исследованиям и энергетике ЕС внес проект резолюции, призывающей к более жестким стандартам по безопасности и окружающей среде на всех находящихся в открытом море нефтяных и газовых скважинах. ${ }^{29}$ Согласно Danish Maritime Magazine, если бы эти за-

25 Miranda A. Schreurs, "Federalism and the Climate: Canada and the European Union," International Journal 66:1 (2010-11): 91-108.

26 Там же.

27 United Kingdom Parliamentary Office of Science and Technology, "Sea Level Rise," Postnote 363 (September 2010).

28 Arno Behrens, "The Role of Renewables in the Interaction Between Climate Change Policy and Energy Security in Europe," Renewable Energy Law and Policy Review 1 (2010): 5-15.

29 European Parliament, Committee on Industry, Research, and Energy, "Offshore Oil and Gas Drilling: Tougher Environment and Safety Standards Needed” (12 July 2011); доступно на 
коны прошли в целостном виде, временно было бы приостановлено любое глубоководное бурение в Арктике. ${ }^{30}$ Вместо этого 13 сентября 2011 года Парламент ЕС принял документ Лицом к лицу с проблемой безопасности при нефтяных и газовых разработках в открытом море, который настаивает на принятии более жестких требований к компаниям, желающим получить лицензии на исследование и эксплуатацию. Дополнительно промышленность должна показать способность полностью принять на себя расходы на очистку и компенсацию пострадавших в случае аварии или посредством страховки, или посредством мутуализации индустрии. ${ }^{31}$

Когда Европейский парламент принял Политику устойчивого развития для Крайнего Севера в 2011 году, парламент защищал позицию «широких всеохватных, ориентированных на экосистему подходов, которые в наибольшей степени могли бы справиться с множеством вызовов перед Арктикой, относящихся к климатическим изменениям». ${ }^{32}$ Однако, во время парламентских дебатов, предшествующих голосованию, один из критиков констатировал: «Похоже, наметился очень незначительный сдвиг ... в нашем мышлении, в сторону безопасности; безопасности энергийных поставок и безопасности при использовании ресурсов». ${ }^{33} \mathrm{~B}$ самом деле, конфиденциальный документ Министерства иностранных дел Объединенного королевства, попавшего в руки Гринпис раскрывает, что Объединенное королевство рассматривало вопрос «как лучшим образом поддержать» участие Шелл и Бритиш Петролеум в русском газовом проекте Сахалин-2. Объединенное королевство является крупнейшим инвестором в энергийном секторе России и демонстрирует существенный интерес в бурении и морских перевозках в Арктике. ${ }^{34}$ Естественно, стратегии ЕС в Арктике не хватает четкости, может быть в результате его слабой позиции, пока ЕС дожидается места в Арктическом совете.

В настоящее время ЕС расхваливает базированную на выгодных параграфах Конвенции ООН по морскому праву (КООНМП) систему управления в Арктике.

www.europarl.europa.eu/en/pressroom/content/20110614IPR21329/html/Offshore-oil-and-gasdrilling-tougher-environment-and-safety-standards-needed.

30

"EU Wants Deepwater Drilling in the Arctic Stopped," Danish Maritime Magazine (13 July 2011); доступно на www.danishmaritimemagazine.com/Nyheder/nyhed.aspx?NewsID=13302 \&Titel=EU\%20wants\%20deepwater\%20drilling\%20in\%20the\%20Arctic\%20stopped.

31 European Parliament, "On facing the challenges of the safety of offshore oil and gas activities" (13 September 2011); доступно на www.europarl.europa.eu/sides/getDoc.do?pubRef=-//EP// TEXT+TA+P7-TA-2011-0366+0+DOC+XML+V0//EN.

32 European Parliament, A Sustainable EU Policy for the High North (A7-0377/2010) (Strasbourg, 20 January 2011).

33 European Parliament, A Sustainable EU Policy for the High North (debate) (Strasbourg, 20 January 2011); доступно на www.europarl.europa.eu/sides/getDoc.do?pubRef=-//EP//TEXT +CRE+20110120+ITEM-004+DOC+XML+V0//EN.

34 Greenpeace International, "U.K. Government Documents on Arctic Drilling," greenpeace.org (24 Мау 2011); доступно на http://www.greenpeace.org/international/en/publications/reports/ UK-Government-Documents-on-Arctic-Drilling/UK-Documents-on-Arctic-Drilling and http://www.greenpeace.org/international/en/publications/reports/UK-Government-Documentson-Arctic-Drilling/UK-Document-on-Arctic-Drilling/. 
Др. Джо Борг, бывший комиссар ЕС по морским делам и рыболовству, отмечал, что вызовы и возможности перед Арктикой имеют «по настоящему глобальный характер» и что «ключевыми словами в международной политике в Арктике в 21-ом веке должны быть единство и сотрудничество». ${ }^{35}$ При согласовании своих интересов с КООНКП ЕС стремится «обеспечить или укрепить свой статус в дебате об управлении Арктикой». ${ }^{36}$

Что касается арктических государств, после ратификации КООНМП, каждое государство располагает сроком в десять лет, чтобы заявить свои права на расширенный континентальный шельф. Если заявка будет утверждена, она дает исключительные права на ресурсы, находящиеся на морском дне или под морским дном этой расширенной шельфовой территории. Однако, КООНМП применяется и к странам, не являющимся арктическими государствами. ${ }^{37}$ Действуя как механизм, регулирующий исключительные экономические зоны, КООНМП заодно предполагает свободное использование морей и определяет природные ресурсы как принадлежащие к «общему наследству человечества», в следствии чего ни одно государство не может упражнять неограниченный суверенитет на данную территорию. Когда КООНМП начнет применяться к некартографированным водам с меняющейся конфигурацией арктического морского льда, Паркер Клот предлагает рассчитывать на то, что «КООНМП является гибким документом, основанным на балансировании обычного права на свободное использование морей с тенденцией некоторых государств расширять свои права в сторону морей высоких широт». ${ }^{38}$

И Арктический совет и у Объединенных наций будет своя роль в развитии Арктической стратегии и управлении этим регионом. Все-таки направление, в котором смещается диалог, может определять силу голоса соответствующего действующего лица. Министр иностранных дел Дании Лене Есперсен апеллировал к Арктике-8 полностью поддержать Арктический совет и таким образом избежать его превращения в «эксклюзивный клуб». Если это не сделать, утверждает она, возникает риск формирования параллельного арктического форума в ООН, в котором арктические страны «не имели бы сильного голоса». ${ }^{39}$

35 Joseph Borg, "The European Union's Strategy of Sustainable Management for the Arctic," speech given at the Arctic Frontiers Conference, Tromso, Norway (19 January 2009); доступно на http://ec.europa.eu/maritimeaffairs/speeches/speech190109_en.html.

36 Timo Koivurova, "Protecting the Environment or Preventing Military Conflicts?: Policy Dynamics," Environmental Policy and Law 40:4 (2010): 170.

37 Michael Byers, "Cold Peace: Arctic Cooperation and Canadian Foreign Policy," International Journal (Autumn 2010): 899-912.

38 Parker Clote, "Implications of Global Warming on State Sovereignty and Arctic Resources under the United Nations Convention on the Law of the Sea: How the Arctic is no Longer communis omnium naturali jure," Richmond Journal of Global Law and Business 8 (2008): 195.

39 "New Strategy Outlines Denmark's Arctic Engagement," People's Daily Online (23 August 2011); доступно на http://english.peopledaily.com.cn/90777/90853/7577436.html. 


\section{Заключение}

Существует ли потенциальная возможность союза ПСИ-ЕС по стратегии, связанной с климатическими изменениями. Да, если каждая из этих организаций решит отложить в сторону свои весьма отличающиеся истории колониальной практики с тем, чтобы обратиться лицом к более важному вызову: долгосрочную экологическую безопасность. Пока мы дожидаемся всеохватного международного соглашения по климатическим изменениям, такие трансграничные ассоциации как ЕС и ПСИ остаются единственной надеждой на нахождение креативных решений глобальных проблем. 


\section{Литература}

"New Strategy Outlines Denmark’s Arctic Engagement." People's Daily Online (2011).

Behrens, Arno. "The Role of Renewables in the Interaction Between Climate Change Policy and Energy Security in Europe." Renewable Energy Law and Policy Review 1 (2010): 5-15.

Bloomfield, Lincoln P.. " The Arctic: Last Unmanaged Frontier." Foreign Affairs 60, no. 1 (2010).

Borg, Joseph. The European Union's Strategy of Sustainable Management for the Arctic In Arctic Frontiers Conference. Tromso, Norway, 2009.

Byers, Michael. "Cold Peace: Arctic Cooperation and Canadian Foreign Policy." International Journal (2010): 899-912.

Chung, Emily. "Arctic Permafrost Thaw Will Boost Carbon Emissions." CBC News: Technology and Science (2011).

Clote, Parker. "Implications of Global Warming on State Sovereignty and Arctic Resources under the United Nations Convention on the Law of the Sea: How the Arctic is no Longer communis omnium naturali jure." Richmond Journal of Global Law and Business 8 (2008).

Dalby, Simon. "Security and Ecology in the Age of Globalization." Environmental Change and Security Project Report 8 (2002).

European Commission, Climate Action: The EU Climate and Energy Package ., 2010.

Ghoneim, Abdel. "Meeting the Challenges of Arctic Development." Offshore Magazine web-cast (2011).

Lacey, Stephen. "After North Sea Oil Spill, Shell Plans to Continue Arctic Drilling." Grist (2011).

Lynch, Patrick. "Arctic Sea Ice Continues Decline, Hits 2nd-Lowest Level." NASA News Feature (2011).

Lynge, Aqqaluk. Strengthening Culture through Change: Will Climate Change Strengthen or Destroy Us., 2009.

Ma, Jianmin, Chongguo Tian, Roland Kallenborn, and Hayley Hung. "Revolatilization of Per-sistent Organic Pollutants in the Arctic Induced by Climate Change." Nature Climate Change 1, no. 5 (2011).

Offerdal, Kristine. "Arctic Energy and EU Policy: Arbitrary Interest in the Norwegian High North." Arctic 63:1 (200): 30-42. 
Rogers, Sarah. "Arctic Resource Development Inevitable and Safe: Greenland." Nunatsia-konline.ca (2011).

Schreurs, Miranda A.. "Federalism and the Climate: Canada and the European Union." International Journal 66:1 (2010).

Shadian, Jessica. "From States to Polities: Reconceptualizing Sovereignty through Inuit Governance." European Journal o0lf International Relations 16, no. 3 (2010): 485-510.

Shadian, Jessica. "Remaking Arctic Governance: The Construction of an Arctic Inuit Polity." Polar Record 42 (2006): 249-59.

Stephenson, Scott R., Laurence C. Smith, and John A. Agnew. "Divergent Long-term Trajectories of Human Access to the Arctic." Nature Climate Change (2011): 156-60.

Watt-Cloutier, Sheila. Climate Change and the Arctic: Bringing Inuit Perspectives to Global Attention In Inuit Circumpolar Council, Address to the Norwegian Research and Technology Forum in cooperation with the Carnegie Institution second Trans-Atlantic Cooperative Research Conference, "Meeting the Climate-Energy Challenge. Washington, D.C, 2004.

Yeager, Brooks B.. "The Ilulissat Declaration: Background and Implications for Arctic Governance." In Aspen Dialogue and Commission on Arctic Climate Change., 2008. 